\title{
Development of a formal system for representing behaviour change theories
}

\author{
Robert West ${ }^{1^{*}}$ \\ Cristina A. Godinho $0^{2,3}$ \\ Lauren Connell Bohlen ${ }^{2,4}$ \\ Rachel N. Carey ${ }^{2,5}$ \\ Janna Hastings ${ }^{6}$ \\ Carmen E. Lefevre ${ }^{2,7}$ \\ Susan Michie ${ }^{2}$
}

\footnotetext{
${ }^{1}$ Department of Behavioural Science and Health, University College London, WC1E 7HB, UK

${ }^{2}$ Centre for Behaviour Change, University College London, WC1E 7HB, UK

${ }^{3}$ Instituto Universitário de Lisboa (ISCTE-IUL), CIS-IUL, Lisboa, Portugal

${ }^{4}$ Department of Kinesiology, University of Rhode Island, Kingston, RI, USA, 02881

${ }^{5}$ Zinc, 23 Tileyard Studios, Tileyard Road, London N7 9AH.

${ }^{6}$ Department of Biological Sciences, University of Cambridge, CB2 1RX, UK

${ }^{7}$ Healthbridge Ltd, London, EC1V 1NY

${ }^{*}$ Corresponding author
} 


\begin{abstract}
Use of natural language to represent behaviour change theories has resulted in lack of clarity and consistency hindering comparison, integration, development and use. This paper describes development of a formal system for representing behaviour change theories which aims to improve clarity and consistency. A given theory is represented in terms of 1 ) its component constructs (e.g., 'self-efficacy', 'perceived threat', 'subjective norm') which are labelled and defined, and 2) relationships between pairs of constructs, which may be causal, structural, or semantic. This formalism appears adequate to represent five commonly used theories (Health Belief Model, Information-Motivation-Behavioural Skill Model, Social Cognitive Theory, Theory of Planned Behaviour, and the Transtheoretical Model). Theory authors and experts judged that the system was able to capture the main propositions of the theories. Following this proof-of-concept, the next step is to assess how far the system can be applied to other theories of behaviour change.
\end{abstract}

Keywords: Behaviour change, theories, theoretical construct, definitions, theory representation, methodology. 
Behaviour change lies at the heart of many challenges facing society, such as improving public health and environmental sustainability ${ }^{1,2}$. Over the last century, a wide range of theories have been developed seeking to explain the processes underlying behaviour change for use in behaviour change interventions ${ }^{3}$. There is a need for theories to be represented in a more consistent and less ambiguous way to allow better comparison, integration, development and use. This paper describes initial development and evaluation of a formal system designed to achieve this.

The term 'theory' has been defined in many ways ${ }^{4}$. One definition agreed by a multi-disciplinary panel of experts from psychology, sociology, anthropology and economics is 'a set of concepts and/or statements which specify how phenomena relate to each other, providing an organising description of a system that accounts for what is known, and explains and predicts phenomena' ${ }^{3}$. In this paper we use the term 'constructs' rather than 'concepts'. Constructs are representations of things that are believed to exist in the world, including objects, processes and their attributes.

Theories can benefit scientific investigation and its application in several ways. They can summarise the current state of knowledge, broaden understanding, and stimulate the generation of new knowledge. They can help to structure thinking and guide research, providing a framework that facilitates communication across research groups ${ }^{5}$. Importantly, theories can provide a basis for intervention development ${ }^{4,6,7}$, and evaluations of theory-based interventions can provide empirical tests of theories ${ }^{8}$.

Reviews of behaviour change theories have noted that they are often not clearly specified nor capable of generating clear and accurate predictions ${ }^{9-13}$. Moreover, the informal ways in which they tend to be presented limit direct comparison and integration ${ }^{14,15}$. Advancing the science of behaviour change, and the application of that science, requires us to be able to compare theories in terms of their content, scope and predictions as a basis for selecting, integrating and modifying them.

Possibly as a result of this, intervention development has been largely disconnected from explicit theories. A majority of behaviour change interventions reported in published evaluations either make no reference to theory or apply it partially and inconsistently ${ }^{15-17}$. Clearer specification of these theories should increase their usefulness in intervention development and evaluation.

A review of 83 behaviour change theories revealed several potential areas for improvement ${ }^{3,14}$. First, where theories overlap in scope it is important to be clearer about the precise differences between them and the reasons for this. Secondly, it is important for theories to be clear about why they only include a limited subset of the constructs that appear to be relevant. Thirdly, theories are expressed using natural language, sometimes supplemented by diagrams that are constructed adhoc without a clear indication of what all the components are intended to represent. Natural language is efficient and highly expressive but introduces ambiguity by virtue of uncertain meaning of terms and a heavy reliance on context to disambiguate them. Different labels are used for the same construct even within a given theory; different theories use different labels for the same construct or the same label for different constructs.

A number of frameworks and resources have been used to organise the large number of constructs in the behaviour change literature. One approach is exemplified by the US National Institute of Health's 'Grid Enabled Measures' (GEM) web-based database. GEM provides descriptions of constructs, as well as measures for their assessment (https://www.gem-

beta.org/Public/Home.aspx). However, it does not seek to compare or integrate constructs. A second approach has been to synthesise constructs from different theories. The Science of 
Behaviour Change (SOBC) project is building a repository of measures of 'mechanisms of action' (https:scienceofbehaviorchange.org/measures). The Theoretical Domains Framework (TDF) identified 128 constructs from 33 theories of behaviour and integrated these into a framework, consisting of 14 theoretical domains ${ }^{12,18}$. While valuable, the GEM repository, the SOBC project and the TDF have not attempted to improve or standardise how theories are represented.

We aimed to develop, and undertake initial evaluation of, a formal system for representing theories of behaviour change that would improve their clarity and facilitate their comparison, integration, development and use. We did this by taking five commonly used theories and attempting to represent them using such a formalism. We then sought to assess their faithfulness to the theories through discussion with theory authors and experts. It is important to note that the goal was to represent the theories as accurately as possible and not to evaluate them. The next step would be to establish whether this formal system could be extended to other behaviour change theories.

\section{Results}

\section{Constructs and their definitions}

Table 1 shows the labels and definitions of main constructs identified in the five theories.

A total of 85 constructs were identified but these were not necessarily distinct; for example the Information-Motivation-Behavioural Skills model uses constructs from the Theory of Planned Behaviour. Some constructs were collections of other constructs (e.g., 'demographic variables' is a construct that includes attributes such as 'age', 'sex', etc.). Some of the constructs are attributes of individuals that are potentially modifiable (e.g., 'perceived susceptibility'), while others are modifiable attributes of the environment (e.g., 'cues to action'), and others are unmodifiable or structural attributes (e.g., 'age').

Table 1: Construct labels and definitions for five theories of behaviour change

\begin{tabular}{|c|c|c|}
\hline Theory $^{1}$ & Construct Label & Construct Definition \\
\hline HBM & 1. Demographic variables & $\begin{array}{l}\text { Variables representing demographic attributes of people, } \\
\text { such as age and gender }\end{array}$ \\
\hline HBM & 2. Socio-psychological variables & $\begin{array}{l}\text { Variables representing social, emotional, cognitive and } \\
\text { behavioural attributes of people }\end{array}$ \\
\hline HBM & 3. Structural variables & $\begin{array}{l}\text { Variables that affect people's perceptions and thus indirectly } \\
\text { influence health-related behaviour (e.g. knowledge about a } \\
\text { disease, prior experience of a disease) }\end{array}$ \\
\hline HBM & 4. Perceived threat & $\begin{array}{l}\text { Perception of the personal threat posed by a particular } \\
\text { disease or health problem }\end{array}$ \\
\hline HBM & 5. Perceived susceptibility & $\begin{array}{l}\text { Perception of the personal risk of contracting a particular } \\
\text { disease or developing a particular health problem }\end{array}$ \\
\hline HBM & 6. Perceived severity & $\begin{array}{l}\text { Perception of the seriousness of the disease and associated } \\
\text { emotional arousal elicited by thoughts of the disease and the } \\
\text { anticipated difficulties that could be caused by the disease }\end{array}$ \\
\hline HBM & 7. Perceived benefits & $\begin{array}{l}\text { Beliefs about the relative effectiveness of specified options } \\
\text { for reducing a health threat, distinct from objective facts }\end{array}$ \\
\hline HBM & 8. $\quad$ Perceived barriers & $\begin{array}{l}\text { Beliefs about the negative attributes of health-protective } \\
\text { action (e.g., inconvenience, expense, discomfort) }\end{array}$ \\
\hline HBM & 9. Self-efficacy & $\begin{array}{l}\text { Beliefs about how far one is capable of taking a health- } \\
\text { protective action }\end{array}$ \\
\hline
\end{tabular}




\begin{tabular}{|c|c|c|}
\hline HBM & 10. Cues to action & $\begin{array}{l}\text { Events that may elicit a health-protective action, which can } \\
\text { be either internal or external }\end{array}$ \\
\hline HBM & $\begin{array}{l}\text { 11. Likelihood of a health- } \\
\text { protective action }\end{array}$ & $\begin{array}{l}\text { The probability of taking action designed to prevent or } \\
\text { mitigate threat to health }\end{array}$ \\
\hline IMB & $\begin{array}{l}\text { 1. Enactment of AIDS } \\
\text { preventive behaviour }\end{array}$ & Specific AIDS risk-reducing acts \\
\hline IMB & $\begin{array}{l}\text { 2. Complexity of AIDS } \\
\text { preventive behaviour }\end{array}$ & $\begin{array}{l}\text { An attribute of specific AIDS risk-reducing acts which means } \\
\text { that it requires complex behavioural skills }\end{array}$ \\
\hline IMB & $\begin{array}{l}\text { 3. Performance of behavioural } \\
\text { Skills }\end{array}$ & $\begin{array}{l}\text { Objective and perceived abilities or proficiencies acquired } \\
\text { through training and practice; the mechanisms through which } \\
\text { information and motivation generally exert an influence on } \\
\text { behaviour }\end{array}$ \\
\hline IMB & 4. Information ${ }^{2}$ & Knowledge about how HIV is transmitted and prevented \\
\hline IMB & 5. Motivation & $\begin{array}{l}\text { The impetus that gives purpose or direction to initiate and } \\
\text { maintain behaviours (e.g., preventative behaviours). } \\
\text { Comprised of attitudes, social norms, and their interrelations } \\
\text { consistent with their specification in the TPB and Theory of } \\
\text { Reasoned Action. }\end{array}$ \\
\hline IMB & $\begin{array}{l}\text { 6. Information about means of } \\
\text { transmission }\end{array}$ & Specific knowledge about how HIV is transmitted \\
\hline IMB & $\begin{array}{l}\text { 7. Information about means of } \\
\text { prevention }\end{array}$ & Specific knowledge about how HIV is prevented \\
\hline IMB & $\begin{array}{l}\text { 8. Decision rules about } \\
\text { transmission and prevention }\end{array}$ & $\begin{array}{l}\text { Heuristic strategies for problem solving/decision-making that } \\
\text { provide an efficient means for making somewhat automatic } \\
\text { decisions regarding the behaviour }\end{array}$ \\
\hline IMB & $\begin{array}{l}\text { 9. Implicit theories about risk } \\
\text { and prevention }\end{array}$ & $\begin{array}{l}\text { More complex sets of beliefs that require cognitive effort to } \\
\text { apply in safer sex decisions, }\end{array}$ \\
\hline IMB & 10. Attitudes $^{2}$ & $\begin{array}{l}\text { Individuals' favourable to unfavourable evaluation of } \\
\text { personally performing a specified HIV preventive behaviour } \\
\text { within a given time frame and context. The basic } \\
\text { psychological underpinnings of attitudes towards an HIV } \\
\text { preventive act involve the sum of beliefs about the } \\
\text { consequences of a behaviour multiplied by evaluations of the } \\
\text { consequences of the behaviour (intended to be the same as } \\
\text { in TPB). }\end{array}$ \\
\hline IMB & 11. Social norms & $\begin{array}{l}\text { Individuals' perception what significant referent others wish } \\
\text { the individual to do with respect to performing a specified } \\
\text { HIV preventive behaviour within a given time frame and } \\
\text { context (intended to be the same as in TPB) }\end{array}$ \\
\hline IMB & 12. Self-efficacy & $\begin{array}{l}\text { Self-belief in one's ability to use one's skills effectively to } \\
\text { carry out behaviour (intended to be the same as in HBM) }\end{array}$ \\
\hline IMB & $\begin{array}{l}\text { 13. Ability to practise self and } \\
\text { partner-reinforcement }\end{array}$ & $\begin{array}{l}\text { The ability to reinforce oneself or one's sexual partner's safer } \\
\text { sex practices }\end{array}$ \\
\hline IMB & 14. Group-specific skills & $\begin{array}{l}\text { Prevention relevant behavioural skills that are pertinent only } \\
\text { to certain groups of people (E.g. substance abuse status, } \\
\text { gender, ethnicity) }\end{array}$ \\
\hline IMB & 15. Self-acceptance of sexuality & The ability to acknowledge that one is sexually active \\
\hline IMB & $\begin{array}{l}\text { 16. Ability to acquire } \\
\text { behaviourally relevant } \\
\text { information }\end{array}$ & $\begin{array}{l}\text { The ability to obtain accurate information about methods of } \\
\text { preventing HIV that can be readily translated into preventive } \\
\text { behaviour by an individual }\end{array}$ \\
\hline IMB & $\begin{array}{l}\text { 17. Ability to negotiate AIDS } \\
\text { prevention with partner }\end{array}$ & $\begin{array}{l}\text { The ability to discuss and agree upon AIDS-preventative } \\
\text { actions with a sexual partner, and to remove oneself from } \\
\text { situations in which safer sex cannot be agreed upon }\end{array}$ \\
\hline IMB & $\begin{array}{l}\text { 18. Ability to practise public } \\
\text { prevention acts }\end{array}$ & $\begin{array}{l}\text { The ability to carry out disease relevant protective } \\
\text { behaviours that must be performed out in the open or not in }\end{array}$ \\
\hline
\end{tabular}




\begin{tabular}{|c|c|c|}
\hline & & $\begin{array}{l}\text { completely private settings (e.g. purchasing condoms and } \\
\text { undergoing HIV testing) }\end{array}$ \\
\hline IMB & $\begin{array}{l}\text { 19. Consistent AIDS prevention } \\
\text { ability }\end{array}$ & $\begin{array}{l}\text { The ability to routinely engage in HIV protective behaviours } \\
\text { over time and situations }\end{array}$ \\
\hline IMB & 20. Beliefs about outcomes & Beliefs about the consequences of a behaviour \\
\hline IMB & 21. Evaluations of outcomes & Evaluations of the consequences of a behaviour \\
\hline IMB & $\begin{array}{l}\text { 22. Beliefs about } \\
\text { support/opposition from } \\
\text { significant others }\end{array}$ & $\begin{array}{l}\text { Having important referent others who support or oppose } \\
\text { one's practice of a particular behaviour }\end{array}$ \\
\hline IMB & $\begin{array}{l}\text { 23. Motivation to comply with } \\
\text { referent others' wishes }\end{array}$ & $\begin{array}{l}\text { Willingness to act in accordance with referent others' } \\
\text { opinions (intended to be the same as TPB) }\end{array}$ \\
\hline SCT & 1. $\quad$ Behaviour & Any action one takes in response to internal/external cues \\
\hline SCT & $\begin{array}{l}\text { 2. Personal and cognitive } \\
\text { factors }\end{array}$ & $\begin{array}{l}\text { Factors relating to the individual and to forms of knowing and } \\
\text { awareness }\end{array}$ \\
\hline SCT & 3. $\quad$ Environment & $\begin{array}{l}\text { The external agents or conditions (physical, biological, social } \\
\text { and cultural) that influence the behaviours of an organism }\end{array}$ \\
\hline SCT & 4. Symbolising capability & $\begin{array}{l}\text { The capacity to use symbols to guide one's behavioural } \\
\text { responses }\end{array}$ \\
\hline SCT & 5. Forethought capability & $\begin{array}{l}\text { The ability to regulate behaviour based on future } \\
\text { expectations }\end{array}$ \\
\hline SCT & 6. Vicarious capability & $\begin{array}{l}\text { The ability to learn through observation of outcomes derived } \\
\text { from the behaviours of others }\end{array}$ \\
\hline SCT & 7. Self-regulatory capability & $\begin{array}{l}\text { The ability to regulate one's own behaviour on the basis of } \\
\text { embedded skills and abilities }\end{array}$ \\
\hline SCT & 8. Self-reflective capability & $\begin{array}{l}\text { The ability to analyse one's own experiences, thoughts and } \\
\text { knowledge based on recalled occurrences }\end{array}$ \\
\hline SCT & 9. Self-efficacy & $\begin{array}{l}\text { Perceived judgements of one's ability to cope effectively in } \\
\text { different circumstances }\end{array}$ \\
\hline SCT & 10. Outcome expectations & $\begin{array}{l}\text { Beliefs about the consequences of undertaking or not } \\
\text { undertaking a behaviour based on their positive and negative } \\
\text { value }\end{array}$ \\
\hline TPB & 1. Behaviour & $\begin{array}{l}\text { The manifest, observable response in a given situation with } \\
\text { respect to a given target }\end{array}$ \\
\hline TPB & 2. Intention & $\begin{array}{l}\text { The cognitive representation of one's readiness to perform } \\
\text { the behaviour; considered to be the immediate antecedent of } \\
\text { behaviour }\end{array}$ \\
\hline TPB & 3. Attitude to the behaviour & $\begin{array}{l}\text { Favourable or unfavourable evaluation or appraisal of the } \\
\text { behaviour }\end{array}$ \\
\hline TPB & 4. Subjective norms & $\begin{array}{l}\text { The perceived social pressure to perform or not to perform } \\
\text { the behaviour }\end{array}$ \\
\hline TPB & $\begin{array}{l}\text { 5. Perceived behavioural } \\
\text { control }\end{array}$ & The perceived ability to perform the behaviour \\
\hline TPB & 6. Actual behavioural control & The actual ability to perform the behaviour \\
\hline TPB & 7. Behavioural belief composite & Sum of behavioural beliefs relating to a given behaviour \\
\hline TPB & 8. $\quad$ Behavioural belief $^{2}$ & $\begin{array}{l}\text { Evaluation of a given outcome from a behaviour formed from } \\
\text { the behavioural belief strength and outcome evaluation }\end{array}$ \\
\hline TPB & 9. Behavioural belief strength & $\begin{array}{l}\text { The perceived probability that performing the behaviour will } \\
\text { lead to the outcome in question }\end{array}$ \\
\hline TPB & 10. Outcome evaluation & Evaluation of a given outcome \\
\hline TPB & 11. Normative belief composite & Sum of normative beliefs \\
\hline TPB & 12. Normative belief ${ }^{2}$ & Normative belief strength multiplied by motivation to comply \\
\hline TPB & 13. Normative belief strength & $\begin{array}{l}\text { The perceived probability that the referent in question } \\
\text { approves of the person performing the behaviour }\end{array}$ \\
\hline TPB & 14. Motivation to comply & $\begin{array}{l}\text { The degree to which someone cares what a given social } \\
\text { referent expects of them }\end{array}$ \\
\hline
\end{tabular}




\begin{tabular}{|c|c|c|}
\hline TPB & 15. Control belief composite & Sum of control beliefs \\
\hline TPB & 16. Control belief ${ }^{2}$ & $\begin{array}{l}\text { Multiple of control belief strength and power of control } \\
\text { factor }\end{array}$ \\
\hline TPB & 17. Power of control factor & $\begin{array}{l}\text { The perceived ability of a given factor to facilitate or inhibit } \\
\text { performance of the behaviour }\end{array}$ \\
\hline TPB & 18. Control belief strength & $\begin{array}{l}\text { The perceived probability that the factor in question is } \\
\text { present }\end{array}$ \\
\hline TTM & 1. Stage of Change & Stage of motivation/readiness to change behaviour \\
\hline TTM & 2. Precontemplation & $\begin{array}{l}\text { Stage at which there is no serious consideration of behaviour } \\
\text { change in the foreseeable future and during which one may } \\
\text { be unaware of any need to / aware but unwilling to / } \\
\text { defensive or resistant to / lack confidence in ability to change }\end{array}$ \\
\hline TTM & 3. Contemplation & $\begin{array}{l}\text { Stage at which there is awareness of a problem and at which } \\
\text { one is seriously considering behaviour change within the next } \\
\text { six months but is not yet committed to act }\end{array}$ \\
\hline TTM & 4. Preparation & $\begin{array}{l}\text { Stage at which one is ready for action and seriously intending } \\
\text { to change within the next month }\end{array}$ \\
\hline TTM & 5. Action & $\begin{array}{l}\text { Stage at which there is significant effort to change behaviour } \\
\text { and where one has met a behaviour-specific criterion }\end{array}$ \\
\hline TTM & 6. Maintenance & $\begin{array}{l}\text { Stage at which behaviour change has been sustained for } \\
\text { more than six months and there is work to prevent relapse }\end{array}$ \\
\hline TTM & $\begin{array}{l}\text { 7. Precontemplation- } \\
\text { contemplation transition }\end{array}$ & $\begin{array}{l}\text { Process of changing stage from Precontemplation to } \\
\text { Contemplation }\end{array}$ \\
\hline TTM & $\begin{array}{l}\text { 8. Contemplation-preparation } \\
\text { transition }\end{array}$ & Process of changing stage from Contemplation to Preparation \\
\hline TTM & 9. $\quad$ Preparation-Action transition & Process of changing stage from Preparation to Action \\
\hline TTM & $\begin{array}{l}\text { 10. Action-Maintenance } \\
\text { transition }\end{array}$ & Process of changing stage from Action to Maintenance \\
\hline TTM & 11. Consciousness raising & $\begin{array}{l}\text { The process of increasing awareness about the problem and } \\
\text { improving the accuracy of information processing about the } \\
\text { problem and about the self }\end{array}$ \\
\hline TTM & $\begin{array}{l}\text { 12. Dramatic relief/emotional } \\
\text { arousal }\end{array}$ & $\begin{array}{l}\text { The process of experiencing and releasing feelings about the } \\
\text { problem and the solution }\end{array}$ \\
\hline TTM & 13. Self re-evaluation & $\begin{array}{l}\text { The process of cognitively and affectively assessing one's self- } \\
\text { image in relation to the problem behaviour }\end{array}$ \\
\hline TTM & 14. Environmental re-evaluation & $\begin{array}{l}\text { The process of cognitively and affectively assessing the ways } \\
\text { in which a personal behaviour might have an impact on the } \\
\text { social environment }\end{array}$ \\
\hline TTM & 15. Social liberation & $\begin{array}{l}\text { The process of noticing social, policy or environmental } \\
\text { changes that facilitate health behaviour change }\end{array}$ \\
\hline TTM & 16. Self liberation & $\begin{array}{l}\text { The process through which one comes to believe in one's } \\
\text { ability to change a particular behaviour and one's } \\
\text { commitment to act on that belief }\end{array}$ \\
\hline TTM & 17. Stimulus control & $\begin{array}{l}\text { The process through which the environment is restructured } \\
\text { (e.g. by the individual) such that cues for problem behaviours } \\
\text { are reduced and cues for healthier behaviours increased }\end{array}$ \\
\hline TTM & 18. Helping relationships & $\begin{array}{l}\text { Relationships characterised by openness, trust and empathy, } \\
\text { which are supportive with regard to the problem behaviour } \\
\text { and health behaviour change }\end{array}$ \\
\hline TTM & 19. Counter conditioning & $\begin{array}{l}\text { The process of adopting healthier behaviours as substitutes } \\
\text { for problem behaviours }\end{array}$ \\
\hline TTM & 20. Reinforcement management & $\begin{array}{l}\text { The process of rewarding oneself, or being rewarded by } \\
\text { others, for making changes; contingency contracts, overt and } \\
\text { covert reinforcement, self-reward }\end{array}$ \\
\hline TTM & 21. Decisional balance & $\begin{array}{l}\text { The process through which the pros and cons of behaviour } \\
\text { change are evaluated }\end{array}$ \\
\hline
\end{tabular}




\begin{tabular}{|l|l|l|}
\hline TTM & 22. Self-efficacy & $\begin{array}{l}\text { One's beliefs about one's ability to carry out a behaviour in } \\
\text { any given situation }\end{array}$ \\
\hline TTM & 23. Temptation & $\begin{array}{l}\text { A desire, or stimulus that creates a desire, to carry out the } \\
\text { problem behaviour(s) }\end{array}$ \\
\hline
\end{tabular}

${ }^{1} \mathrm{HBM}=$ Health Belief Model; SCT=Social Cognitive Theory; IMB=Information Motivation Belief model; TPB=Theory of Planned Behaviour; TTM=Transtheoretical Model. ${ }^{2}$ The terms 'information' and 'attitude' were used by the theory authors but are intended to refer to information and attitudes to HIV-related issues.

\section{Theory representations}

Table 2 shows the accumulated library of relationships and their definitions. These were added incrementally as required to capture the theories, and are only a small set of possible relationships given that theories can specify relationships at any desired level of specificity.

Table 2: Relationships proposed in five theories of behaviour change

\begin{tabular}{|c|c|c|c|}
\hline $\begin{array}{c}\text { Type of } \\
\text { Relationship }\end{array}$ & Label & $\begin{array}{c}\text { Graphical } \\
\text { Representation }\end{array}$ & Definition \\
\hline \multirow[t]{7}{*}{ Causal } & Is influenced by & & $\begin{array}{l}\mathrm{X} \text { is influenced by } \mathrm{Y} \text { if, other } \\
\text { things being equal, a change in } \\
\mathrm{Y} \text { necessitates a change in } \mathrm{X}\end{array}$ \\
\hline & $\begin{array}{l}\text { Is influenced (+) } \\
\text { by }\end{array}$ & + & $\begin{array}{l}X \text { is influenced (+) by } Y \text { if, other } \\
\text { things being equal, a change in } \\
\text { the value of } Y \text { necessitates a } \\
\text { change in the value of } X \text { in the } \\
\text { same direction }\end{array}$ \\
\hline & $\begin{array}{l}\text { Is influenced (-) } \\
\text { by }\end{array}$ & - & $\begin{array}{l}X \text { is influenced (-) by } Y \text { if, other } \\
\text { things being equal, a change in } \\
\text { the value of } Y \text { necessitates a } \\
\text { change in the value of } X \text { in the } \\
\text { opposite direction }\end{array}$ \\
\hline & $\begin{array}{l}\text { May be } \\
\text { influenced by }\end{array}$ & $?$ & $\begin{array}{l}\mathrm{X} \text { may be influenced by } \mathrm{Y} \text { if a } \\
\text { change in } \mathrm{Y} \text { necessitates a } \\
\text { change in } \mathrm{X} \text { only under some } \\
\text { circumstances. The 'may be' } \\
\text { can be combined with other } \\
\text { modifiers such as (+) and (-) to } \\
\text { express the fact that these } \\
\text { more specific relationships } \\
\text { hold true only under at least } \\
\text { some circumstances }\end{array}$ \\
\hline & $\begin{array}{l}\text { Is influenced }(*) \\
\text { by }\end{array}$ & $\longrightarrow$ & $\begin{array}{l}\mathrm{X} \text { is influenced }\left({ }^{*}\right) \text { by } \mathrm{Y} \text { if } \mathrm{X} \text { is a } \\
\text { multiple of } \mathrm{Y}\end{array}$ \\
\hline & $\begin{array}{l}\text { Is influenced } \\
\text { (sum) by }\end{array}$ & Sum & $\begin{array}{l}\mathrm{X} \text { is influenced (sum) by } \mathrm{Y} \text { if } \mathrm{X} \text { is } \\
\text { equal to the sum of values of } \mathrm{Y} \\
\text { where } \mathrm{Y} \text { is a set with one or } \\
\text { more members }\end{array}$ \\
\hline & Correlates with & & $\begin{array}{l}X \text { is correlated with } Y \text { is values } \\
\text { of } X \text { tend to covary with values } \\
\text { of } Y \text { even though the two may }\end{array}$ \\
\hline
\end{tabular}




\begin{tabular}{|c|c|c|c|}
\hline & & & $\begin{array}{l}\text { not be causally linked. If } X \text { is } \\
\text { correlated with } Y, Y \text { is } \\
\text { correlated with } X \text {. }\end{array}$ \\
\hline \multirow[t]{3}{*}{ Semantic } & Type of & Type of & $\begin{array}{l}X \text { is a type of } Y \text { if } X \text { is a more } \\
\text { specific subtype of } Y \text {, i.e. } X \\
\text { possesses all the attributes of } Y \\
\text { but } Y \text { does not possess all the } \\
\text { attributes of } X\end{array}$ \\
\hline & Value of & $\ldots \ldots \ldots \ldots$ Value of $\ldots \ldots \ldots$ & $\begin{array}{l}X \text { is a value of } Y \text { if } X \text { is a type of } \\
Y \text {, all types of } Y \text { are specified in } \\
\text { the model and any use of a } \\
\text { subtype of } Y \text { in the theory must } \\
\text { be one of these }\end{array}$ \\
\hline & Has attribute & ... Has attribute $\ldots$ & $\begin{array}{l}\mathrm{X} \text { has attribute } \mathrm{Y} \text { if } \mathrm{Y} \text { is an } \\
\text { attribute or characteristic of } \mathrm{X}\end{array}$ \\
\hline \multirow[t]{3}{*}{ Structural } & Part of & $--_{\text {Part of }}-\rightarrow$ & $\begin{array}{l}X \text { is a part of } Y \text { if } X \text { is a member } \\
\text { of a group whose members } \\
\text { together comprise } Y\end{array}$ \\
\hline & Has start & -- has start- $\rightarrow$ & $\begin{array}{l}X \text { has start } Y \text { if } X \text { is a transition } \\
\text { and } Y \text { is a value at the temporal } \\
\text { beginning of the transition }\end{array}$ \\
\hline & Has end & -- has end $-\rightarrow$ & $\begin{array}{l}X \text { has end } Y \text { if } X \text { is a transition } \\
\text { and } Y \text { is a value at the temporal } \\
\text { end of the transition }\end{array}$ \\
\hline
\end{tabular}

Figures 1 to 5 show the five theories in terms of their constructs and the relationships between them. Tables 3 to 7 show the propositions in these theories. Each theory representation takes the form of a numbered list of theory propositions in the 'subject-relationship-object' format followed by a diagram. We have devised a number of conventions to interpret this diagram, which are shown in Table 3.

\section{Health Belief Model (HBM)}

Figure 1 and Table 3 show the Health Belief Model (HBM) represented using the proposed formal system. The HBM includes a 'moderating' relationship, whereby cues to action increase the influence of perceived threat on likelihood of preventive action. In the graphical representation, this is depicted by having the arrow ending on the perceived threat-likelihood of preventive action arrow. To represent this using a subject-relationship-object statement, we have to create a construct called the 'perceived threat-likelihood of preventive action relationship'. (See proposition 5 of Table 4.)

\section{Figure 1 about here}

Table 3: Propositions in the Health Belief Model

1. Likelihood of preventive action is influenced (+) by perceived benefits

2. Likelihood of preventive action is influenced (-) by perceived barriers

3. Likelihood of preventive action is influenced $(+)$ by self-efficacy

4. Likelihood of preventive action is influenced $(+)$ by perceived threat

5. Perceived threat-likelihood of preventive action relationship is influenced (+) by cues to action

6. Perceived benefits are influenced by demographic variables

7. Perceived benefits are influenced by social psychological variables

8. Perceived benefits are influenced by structural variables 
9. Perceived barriers are influenced by demographic variables

10. Perceived barriers are influenced by social psychological variables

11. Perceived barriers are influenced by structural variables

12. Self-efficacy is influenced by demographic variables

13. Self-efficacy is influenced by social psychological variables

14. Self-efficacy is influenced by structural variables

15. Perceived severity is part of perceived threat

16. Perceived susceptibility is part of perceived threat

\section{Information-Motivation-Behavioural Skills Model (IMB)}

Figure 2 and Table 4 show the Information-Motivation-Behavioural Skills Model (IMB). We focused on the original version of the model which concerned HIV/AIDS prevention behaviour. The model has since been expanded to cover other health-risk behaviours ${ }^{19}$.

The IMB includes the causal 'is influenced $(*)$ by' relationship, and semantic 'type of' relationship. The latter expresses the idea that one construct is a subclass of another and logically inherits all its properties (e.g., mammal is a subclass of animal, and so mammals can be assumed to have all the properties of animals). Thus, the theory proposes that behavioural skills influence AIDS preventive behaviour and so it follows that all the different types of behavioural skill (e.g., self-efficacy) do so. Note that this relationship is different from the 'part of' relationship. For example, attitudes are deemed to be a part of motivation and so may contribute to it but not everything that is true about motivation would be true of attitudes.

The IMB also includes another semantic relationship: 'has attribute'. Thus, 'complexity' is represented as an attribute of AIDS preventive behaviour. This is used to express the proposition that the more complex the AIDS preventive behaviour is, the less information and motivation can influence it directly and the more it requires behavioural skills.

The IMB requires explicit representation of the idea that an entity may or may not influence another as a function of one or more stated or unstated moderators. We represent this by adding a ? to any given relationship. For example, it is an explicit feature of the theory that 'information' may or may not influence 'motivation'; therefore, we have represented 'Motivation may be influenced by information' by a solid arrow with a ?. Similarly, 'Enactment of AIDS preventive behaviour may be influenced (+) by information' is represented by a solid arrow with +?. In this case, the moderator 'complexity of AIDS preventive behaviour' is explicitly stated. From a logical standpoint this is not necessarily required, but from an accuracy perspective, it captures the original intent of the authors who proposed each theory.

In the graphical representation of the IMB we introduced a 'container' (a box around constructs). The container indicates that all contained constructs have the same relationship with another construct. This is a presentational device to make interpretation of the diagram easier.

Figure 2 about here

Table 4: Propositions in the Information-Motivation-Behavioural Skills Model

1. Enactment of AIDS preventive behaviour is influenced (+) by performance of behavioural skills

2. Enactment of AIDS preventive behaviour has attribute complexity of AIDS preventive behaviour

3. Enactment of AIDS preventive behaviour may be influenced $(+)$ by information

4. Enactment of AIDS preventive behaviour may be influenced $(+)$ by motivation 
5. Information-enactment of AIDS preventive behaviour relationship is influenced ( + ) by complexity of AIDS related behaviour

6. Motivation-enactment of AIDS preventive behaviour relationship is influenced (+) by complexity of AIDS related behaviour

7. Performance of Behavioural skills are influenced $(+)$ by information

8. Performance of Behavioural skills are influenced $(+)$ by motivation

9. Motivation may be influenced by information

10. Information may be influenced by motivation

11. Self-acceptance of sexuality is a type of performance of behavioural skill

12. Ability to acquire behaviourally relevant information is a type of performance of behavioural skill

13. Self-efficacy is a type of performance of behavioural skill

14. Ability to practise self and partner reinforcement is a type of performance of behavioural skill

15. Ability to negotiate AIDS prevention with partner is a type of performance of behavioural skill

16. Ability to perform public prevention acts is a type of performance of behavioural skill

17. Consistent AIDS prevention ability is a type of performance of behavioural skill

18. Group-specific skills are types of behavioural skill

19. Information about means of transmission are types of information

20. Information about means of prevention are types of information

21. Decision rules about transmission and prevention are types of information

22. Implicit theories about risk and prevention are types of information

23. Attitudes are part of motivation

24. Social norms are part of motivation

25. Attitudes are influenced by $\left({ }^{*}\right)$ beliefs about outcomes

26. Attitudes are influenced by $\left({ }^{*}\right)$ evaluation of outcomes

27. Social norms are influenced by $\left({ }^{*}\right)$ beliefs about support/opposition from significant others

28. Social norms are influenced by $\left({ }^{*}\right)$ motivation to comply with referent others' wishes

Social Cognitive Theory (SCT)

Figure 3 and Table 5 show Social Cognitive Theory (SCT). The theory focuses on personal and cognitive factors that are important influences on behaviour and delineates these, expressing complex causal, structural and semantic relationships among them. The formalism, based on the theory propositions found, shows that according to those propositions self-efficacy is not explicitly considered a type of 'personal and cognitive factor' even though the definitions of these constructs suggests that it might be. This illustrates the ability of the formalism to make explicit aspects of theories that theory authors may have left implicit.

Figure 3 about here

Table 5: Propositions of Social Cognitive Theory

1. Behaviour is influenced by environment

2. Behaviour is influenced ( + ) by self-efficacy

3. Behaviour is influenced by personal and cognitive factors

4. Environment is influenced by behaviour

5. Environment is influenced by personal and cognitive factors

6. Personal and cognitive factors are influenced by environment

7. Personal and cognitive factors are influenced by behaviour

8. Self-efficacy is part of self-reflective capability

9. Self-efficacy is influenced $(+)$ by self-regulatory capacity

10. Self-reflective capability is a type of personal cognitive factor 
11. Self-regulatory capability is a type of personal cognitive factor

12. Self-regulatory capability is influenced $(+)$ by vicarious learning capability

13. Self-regulatory capability is influenced $(+)$ by outcome expectations

14. Symbolising capability is a type of personal cognitive factor

15. Forethought capability is a type of personal cognitive factor

16. Forethought capability is influenced (+) by symbolising capability

17. Vicarious learning capability is a type of personal cognitive factor

18. Outcome expectations are part of forethought capability

The Theory of Planned Behaviour (TPB)

Figure 4 and Table 6 show the Theory of Planned Behaviour (TPB). The TPB uses another type of causal relationship 'is influenced (sum) by' to represent the summation of multiple input values to influence the value of an output construct. Thus the construct 'behavioural belief composite' is the sum of a set of individual behavioural beliefs.

Each individual 'behavioural belief' is a multiple of the constructs 'behavioural belief strength' and 'outcome evaluation'. The theory author indicated in his comments that he did not perceive the need for the 'behavioural belief' construct representing each individual behavioural belief, but logically such a construct is required, otherwise there is nothing for the 'behavioural belief strength' and 'outcome evaluation' to multiply to create. We used a similar formulation for influences on 'normative belief composite' and 'control belief composite'.

It may be noted that 'perceived behavioural control' moderates 'intention-behaviour relationship'. This construct was created and labelled as part of the proposed formalism. The version of the theory presented here also includes the construct 'actual behavioural control' which captures the influence of capability and environmental factors on the' intention-behaviour relationship'.

One further addition required for this model was a 'correlates with' relationship. In our initial interpretation of the theory we construed this as a bi-directional causal relationship but the theory author indicated that this was not accurate. We therefore have to presume that 'correlates with' is a bi-directional relationship that proposes an association between two constructs that need not involve a direct cause. We represent this as a double-headed arrow. The TPB does not specify whether the correlations are positive or negative, but as with 'is influenced by' other theories might specify + or - qualifiers.

\section{Figure 4 about here}

Table 6: Propositions the Theory of Planned Behaviour

1. Behaviour is influenced $(+)$ by intention

2. Intention is influenced $(+)$ by attitude to the behaviour

3. Intention is influenced $(+)$ by subjective norm

4. Intention is influenced $(+)$ by perceived behavioural control

5. Intention-behaviour relationship is influenced $\left(^{*}\right)$ by perceived behavioural control

6. Intention-behaviour relationship is influenced (*) by actual behavioural control

7. Attitude to the behaviour is influenced $(+)$ by summed behavioural beliefs

8. Behavioural belief composite is influenced (sum) by behavioural beliefs

9. Behavioural beliefs are influenced $\left({ }^{*}\right)$ by behavioural belief strengths

10. Behavioural beliefs are influenced $(*)$ by outcome evaluations

11. Subjective norms are influenced $(*)$ by normative belief composite

12. Normative belief composite is influenced by (sum) normative beliefs

13. Normative beliefs are influenced $\left({ }^{*}\right)$ by normative belief strength 
14. Normative beliefs are influenced $\left({ }^{*}\right)$ by motivation to comply

15. Perceived behavioural control is influenced $(*)$ by summed control beliefs

16. Perceived behavioural control is influenced $(+)$ by actual behavioural control

17. Control belief composite is influenced (sum) by control beliefs

18. Control beliefs are influenced $(*)$ by control belief strength

19. Control beliefs are influenced $(*)$ by power of control factor

20. Attitude to the behaviour correlates with subjective norms

21. Attitude to the behaviour correlates with perceived behavioural control

22. Subjective norms correlate with perceived behavioural control

The Transtheoretical Model (TTM)

The final theory examined, the Transtheoretical Model (TTM) is different from the previous four in that it focuses on transitions between qualitatively different stages over time and factors that influence stage transitions (Figure 5 and Table 7). A person's stage of change is a measured variable, with each individual stage of change representing one of five possible values of the variable 'stage of change'. All constructs and relationships in the TTM end up influencing the value of the 'stage' variable. To represent this we used the 'value of' semantic relationship as a subclass of 'type of'. Without including 'value of' we would not be able to represent the proposition that different things influence different stage transitions.

The TTM also involves representing the transition from one stage to another as a construct. The transition constructs have 'has start' and 'has end' structural relationships. For example, our specification of the TTM includes the construct 'pre-contemplation to contemplation transition', which starts with 'pre-contemplation' and ends with 'contemplation'. For visual clarity, the graphical representation uses different shapes for constructs that are values and transitions.

Figure 5 about here

Table 7: Propositions of the Transtheoretical Model (TTM)

1. Pre-contemplation is a value of stage of change

2. Contemplation is a value of stage of change

3. Preparation is a value of stage of change

4. Action is a value of stage of change

5. Maintenance is a value of stage of change

6. Precontemplation contemplation transition has start precontemplation

7. Precontemplation contemplation transition has end contemplation

8. Contemplation preparation transition has start contemplation

9. Contemplation preparation transition has end preparation

10. Preparation action transition has start preparation

11. Preparation action transition has end action

12. Action maintenance transition has start action

13. Action maintenance transition has end maintenance

14. Precontemplation contemplation transition is influenced $(+)$ by decisional balance

15. Precontemplation contemplation transition is influenced $(+)$ by self-efficacy

16. Precontemplation contemplation transition is influenced by consciousness raising

17. Precontemplation contemplation transition is influenced by dramatic relief/emotional arousal

18. Precontemplation contemplation transition is influenced by self re-evaluation

19. Precontemplation contemplation transition is influenced by environmental re-evaluation

20. Precontemplation contemplation transition is influenced by social liberation

21. Contemplation preparation transition is influenced $(+)$ by decisional balance

22. Contemplation preparation transition is influenced $(+)$ by self-efficacy 
23. Contemplation preparation transition is influenced by self re-evaluation

24. Contemplation preparation transition is influenced by environmental re-evaluation

25. Contemplation preparation transition is influenced $(+)$ by self-liberation

26. Preparation action transition is influenced $(+)$ by decisional balance

27. Preparation action transition is influenced $(+)$ by self-efficacy

28. Preparation action transition is influenced by self-efficacy temptation combination

29. Preparation action transition is influenced by self-liberation

30. Preparation action transition is influenced by stimulus control

31. Preparation action transition is influenced by helping relationships

32. Preparation action transition is influenced by counter conditioning

33. Action maintenance transition is influenced $(+)$ by decisional balance

34. Action maintenance transition is influenced $(+)$ by self-efficacy

35. Action maintenance transition is influenced by self-efficacy temptation combination

36. Action maintenance transition is influenced by stimulus control

37. Action maintenance transition is influenced by helping relationships

38. Action maintenance transition is influenced by counter conditioning

39. Action maintenance transition is influenced by reinforcement management

40. Action maintenance transition is influenced by self-liberation

41. Self-efficacy temptation combination is influenced by self-efficacy

42. Self-efficacy temptation combination is influenced by temptation

\section{Evaluation of theory specification}

In all five theories, the theory authors appeared to be satisfied that the modelling system was able to capture their theories adequately. As noted earlier, the Theory of Planned Behaviour author did not consider that constructs such as 'behavioural beliefs' were required but logic dictated that these be specified and given a label since they captured a defined constructs within the theory. The Transtheoretical Model author noted that the model as represented here did not capture transition back to earlier stages of change and processes that might influence these but noted that this would be possible using the formal system we were using.

\section{Discussion}

Our formal system was found to be capable of representing the five selected behaviour change theories. The process of deriving the representations helped to clarify interpretations of the theories through dialogue with theory authors and experts.

The theory representation method chosen was one of many possible options. Some behaviour change theories are efficiently expressed as sets of equations, while others are naturally expressed in terms of micro- or macro-simulations such as Agent Based Models, Bayesian nets or Markov processes ${ }^{20}$. We believe that the chosen system can encompass those other systems as well as theories that want to retain the expressiveness of natural language.

Another outcome from the process of specifying theories is highlighting the need for greater clarity and consistency in defining constructs. The definitions obtained from the literature involved a great deal of implicit meaning and in some cases did not appear to capture fully the construct as intended. It is also apparent that some constructs are common to more than one theory, although whether they are precisely the same or whether the theory authors consider there to be important differences is not clear.

Developing this theory representation system highlighted the importance in theories of being more precise about the nature of complex causal interactions. The Theory of Planned Behaviour, for 
example, contains two different kinds of causal interaction: 1) 'multiplicative' relationships between factors contributing to behavioural beliefs, subjective norms and perceived behavioural control, and 2) a 'moderating' relationship of 'actual behavioural control' over the 'intention-behaviour relationship'. Both of these can be handled in this modelling system and in principle any complexity of interaction can be handled. For example, in principle someone could specify another variable moderating the moderating relationship between 'actual behavioural control' and the 'intentionbehaviour relationship'. In practice, such higher-order interactions are very challenging to test in empirical studies but the potential to represent them in this formalism exists.

Once a database of theories represented using the proposed system is created, computational methods can be used for searching, comparing and integrating. Possible operations include:

1. Simple searching for constructs that have similar labels or definitions: for example to find all theories that use the construct label, 'self-efficacy' or 'intention'.

2. 'Semantic searching' to find constructs that have similar properties even though they may have different labels and definitions.

3. Searching for properties of constructs: for example what are the factors that have been proposed to influence self-efficacy and what has it been postulated to influence?

4. Precisely delineating areas of overlap and difference between theories: for example, specifying precisely how recently developed theories such as I-Change ${ }^{21}$ compare to earlier ones such as the Theory of Planned behaviour and the Health Belief Model.

5. Clustering theories to identify theory classes: for example, based on similarity indices based on overlap in constructs and proposed relationships.

6. Building a 'canonical' theory that includes key relationships and constructs from the corpus of theories: for example, by creating an aggregated list of constructs, selecting ones that are most representative of sets that are similar, and building a specification that captures all their proposed inter-relationships.

7. Reasoning with theories to assess differential predictions from different theories covering the same domain: for example, specifically predicting which constructs would be expected to impact on behaviour change in defined behaviours, populations and settings.

The current study was limited in terms of the number of theories that it covered. It is possible that there are theories in the literature that could not be specified using this system. However, the theories included to date were diverse and we are already advanced with work to specify another 77 theories which we will report on in a subsequent publication.

Another potential limitation is that the formal system has not yet been formally linked to modelling languages used in other domains such as OWL (Web Ontology Language; www.w3.org/OWL/). These modelling languages allow potentially greater expressivity than the system used here and include a large set of formalisms and axioms that can be used to generate automated inferences. This is something that will done in parallel with the next phase of the project.

A third limitation is that the theory representations were only used to capture the main parts of the theories. We believe that it is straightforward to add further propositions to the theories but the graphical representations would likely become very difficult to read. Finding a way to present complex theories in graphical form is always going to be challenging but merits serious consideration, including input from specialists across different disciplines.

\section{Conclusions}


It appears to be possible to represent major behaviour change theories using a standard system of binary relationships between defined constructs. This system could be used both for reformulating existing theories and for developing new ones. This would set the scene for a more systematic approach to theory development and use. The implication for scientific advance is that the system allows for comparison across the large number of behaviour change theories to identify the frequently occurring constructs and relationships, enabling the development of a smaller number of canonical theories and providing a coherent basis for advance. It allows for more specific testing of theories and reporting of findings in a fashion that supports the efficient accumulation of knowledge. An important implication for practice is that identifying a few theories that summarise core theoretical knowledge about behaviour change will enable those wishing to apply theory, but are currently overwhelmed with the large number of theories, to use those summary theories to develop and evaluate interventions and to inform syntheses of evidence about behaviour change.

\section{Method}

\section{Theory selection}

We selected five theories from the 83 reviewed by Davis et al 3,14. They were the most frequently used behaviour change theories as identified by previous reviews of behaviour change interventions for a range of health behaviours, including healthy eating, physical activity, and sexual behaviours 3,15,22: the Health Belief Model (HBM) ${ }^{23}$, the Information-Motivation-Behavioural Skill Model (IMB) ${ }^{24}$, Social Cognitive Theory (SCT) ${ }^{25}$, the Theory of Planned Behaviour (TPB) ${ }^{26}$, and the Transtheoretical Model (TTM) ${ }^{27}$.

\section{Choice of a formal representation system}

Behaviour change theories describe causal influences between variables such that a change in one variable results in a change in another. They also describe processes of change in which events lead to other events or values of a variable change over time as a function of other variables and events. These causal influences may themselves be influenced or 'moderated' by other variables or processes, and variables or processes may 'mediate' causal influences between other variables or processes.

Models of this kind can be represented as sets of expressions of the form 'subject-relationshipobject'. The subject and object are the constructs, and the relationship links the subject to the object. Subject-relationship-object expressions can be represented graphically by labelled boxes with labelled arrows linking them. They can be used to create formal 'ontologies': data structures that represent knowledge in terms of 'entity' identifiers, labels, definitions and relationships between them ${ }^{28}$.

Figure 6 gives a simple example of a graphical representation of a simple behaviour change theory represented in this way. The arrows represent the relationship 'positively influences'. The diagram represents dyadic relationships between variables for a given behaviour: habit strength positively influences behaviour frequency, desire strength positively influences behaviour frequency, and opportunity frequency positively influences behaviour frequency.

\section{Figure 6 about here}

Causal models represented in this way are used in many areas of study including psychology, economics, biology, and public health ${ }^{29}$. They allow direct and indirect paths of influence to be traced between variables. The relationships in subject-relationship-object expressions need not be 
limited to causal ones; they can represent any relationship in which two constructs may be linked with each other (e.g., 'is a type of' as in 'disgust is a type of emotion').

The ability to form expressions linking two constructs with any type of relationship can provide a flexible and intuitive system which could be suitable for representing behaviour change theories. We applied it to the five selected behaviour change theories using a two-step process. For each theory: 1) we identified labels and definitions for each construct in each theory, and 2) we expressed propositions within the theory in terms of defined relationships between the constructs, building a library of defined relationships as required.

A database of theories constructed in this way can provide the basis for search, comparison, integration, development and use. The database can be searched for construct labels or definitions; similarities and differences can be identified; relationships with other constructs can be compared; propositions can be combined or merged; specific propositions can be extracted from theories and tested; propositions can be added, removed or modified; and causal chains can be used to identify intervention targets.

\section{Construct identification and definition}

We identified construct labels (e.g., 'self-efficacy') from the original published descriptions of the theories ${ }^{14}$. Construct definitions were generated in several steps. They were drafted by KS, RC and/or LC (see authors and acknowledgements) based on the natural language expressions of the theories. They were then reviewed by two additional authors. If no definition was found within the theoretical statements, the dictionary of the American Psychological Association ${ }^{30}$ was consulted. If no definition was found here, other dictionaries and sources were consulted (e.g., Oxford English Dictionary, Merriam-Webster Dictionary, Wikipedia). If it was not possible to find an appropriate definition using any of these sources, definitions were created drawing upon the original theory text and dictionary definitions for words within the construct label.

The draft labels and definitions were reviewed by the study leads, RW and SM, and then sent to the theory authors to review for accuracy. For authors with whom contact could not be made, theory experts were identified and contacted. These experts were found by searching the Web of Science and Scopus databases for authors who had cited the theory most frequently, and then examining published articles by these authors for relevance. Where theory authors or experts proposed modification, addition or removal of theory constructs, these changes were either included or an explanation provided as to why not.

\section{Theory representation}

To express propositions within the theories, we identified three broad types of relationship that could be used: causal, semantic, and structural. A causal relationship would be of the kind ' $X$ is influenced by $Y$ '. If $X$ and $Y$ are variables this means that if values of $X$ change, then other things being equal, so do values of $\mathrm{Y}$. If $\mathrm{X}$ is a process it means that $\mathrm{X}$ leads to $\mathrm{Y}$. The nature of the dependency may be more or less specific and may take different forms as in ' $X$ is positively influenced by $Y^{\prime}$ or ' $X$ is proportional to $Y^{\prime}$. What we are calling a semantic relationship would be of the kind ' $X$ is a type of $Y$ ' or ' $X$ has attribute $Y$ '. A structural relationship would be of the kind ' $X$ is a part of $Y^{\prime}$. Table 8 gives examples of the three types of relationship.

Table 8: Basic types of relationship

\begin{tabular}{|l|l|l|}
\hline Type of relationship & Basic relationship & Examples \\
\hline
\end{tabular}




\begin{tabular}{|l|l|l|}
\hline Causal & influenced by & $\begin{array}{l}\text { Biology: } \text { Height is influenced by level of } \\
\text { production of growth hormone } \\
\text { Behaviour change: } \text { Strength of intention to } \\
\text { perform a behaviour is influenced by attitude } \\
\text { towards the behaviour }\end{array}$ \\
\hline Semantic & $\begin{array}{l}\text { Biology: Dogs are a type of mammal } \\
\text { Behaviour change: Information about } \\
\text { consequences of a behaviour is a type of } \\
\text { information }\end{array}$ \\
\hline Structural & $\begin{array}{l}\text { Biology: } \text { Ribs are a part of the skeleton } \\
\text { Behaviour change: Perceived severity is a part } \\
\text { of perceived threat }\end{array}$ \\
\hline
\end{tabular}

Each type of relationship is directional. Some could, in principle, be expressed in the reverse direction (e.g., 'influences' versus 'is influenced by'). The choice of direction in those cases is determined by how one wants the model to operate. In the case of behaviour change models the aim is generally to predict and explain behaviour and so we judged it to be natural to make the entity being explained or predicted as the subject of each causal relationship (variants of 'is influenced by' rather than 'influences').

To represent the constructs and relationships comprising a theory in an accessible visual format, we created a graphical system of representation using Lucid Chart software (www.lucidchart.com). A useful feature of this software is that the resulting diagrams can be exported to a database as a list of 'subject-relationship-object' triads (e.g., 'behaviour frequency', 'is positively influenced by', 'strength of desire').

Two researchers (SM and CG) independently created formal representations of the five theories in terms of subject-relationship-object triads. Each theory was then discussed with the other members of the research team until an agreed version was arrived at. This diagram (with accompanying theory representation in the form of subject-relationship-object propositions) was then sent to theory authors or experts for comment and revised to reflect their views.

\section{Data availability}

N/a

\section{Code availability}

N/a 


\section{Figure captions}

Figure 1: Example of a simple causal model of behaviour

Figure 2: Representation of the Health Belief Model

Figure 3: Representation of the Information Motivation Behavioural Skills Model (IMB)

Figure 4: Representation of Social Cognitive Theory

Figure 5: Representation the Theory of Planned Behaviour

Figure 6: Representation of the Transtheoretical Model (TTM) 


\section{References}

1 Green, L. W., Hiatt, R. A. \& Hoeft, K. S. in Oxford Textbook of Global Public Health (eds R Detels, M Gulliford, Q Karim, \& C Chuan) 218-233 (Oxford University Press, 2015).

2 Vlek, C. \& Steg, L. Human Behavior and Environmental Sustainability: Problems, Driving Forces, and Research Topics. Journal of Social Issues 63, 1-19 (2007).

3 Davis, R., Campbell, R., Hildon, Z., Hobbs, L. \& Michie, S. Theories of behaviour and behaviour change across the social and behavioural sciences: a scoping review. Health psychology review 9, 323-344 (2015).

4 Glantz, K., Rimer, B. \& K, V. (Jossey-Bass, California, 2015).

5 Craig, P. et al. Developing and evaluating complex interventions: the new Medical Research Council guidance. British Medical Journal 337, doi:10.1136/bmj.a1655 (2008).

6 Glanz, K. \& Bishop, D. B. The role of behavioral science theory in development and implementation of public health interventions. Annual review of public health 31, 399-418 (2010).

$7 \quad$ Lippke, S. \& Ziegelmann, J. P. Theory-based health behavior change: Developing, testing, and applying theories for evidence-based interventions. Applied Psychology 57, 698-716 (2008).

8 West, R. \& Michie, S. A Guide to the Development and Evaluation of Digital Behaviour Change Interventions. (Silverback Publishing, 2016).

9 Armitage, C. J. \& Conner, M. Social cognition models and health behaviour: A structured review. Psychology and health 15, 173-189 (2000).

10 Gebhardt, W. A. \& Maes, S. Integrating social-psychological frameworks for health behavior research. American Journal of Health Behavior 25, 528-536 (2001).

11 Kirscht, J. P. Preventive health behavior: A review of research and issues. Health Psychology 2, 277 (1983).

12 Michie, S. et al. Making psychological theory useful for implementing evidence based practice: a consensus approach. BMJ Quality \& Safety 14, 26-33 (2005).

13 Garnett, C. et al. Reported Theory Use by Digital Interventions for Hazardous and Harmful Alcohol Consumption, and Association With Effectiveness: Meta-Regression. Journal of medical Internet research 20, e69, doi:10.2196/jmir.8807 (2018).

14 Michie, S., West, R., Campbell, R., Brown, J. \& Gainforth, H. ABC of Behaviour Change Theories: An Essential Resource for Researchers, Policy Makers and Practi. (Silverback Publishing, 2014).

15 Prestwich, A. et al. Does theory influence the effectiveness of health behavior interventions? Meta-analysis. Health Psychology 33, 465-474 (2014).

16 Dombrowski, S. U., Sniehotta, F. F., Avenell, A. \& Coyne, J. C. Towards a cumulative science of behaviour change: do current conduct and reporting of behavioural interventions fall short of best practice. Psychol Health 22, 869-874 (2007).

17 Michie, S. \& Prestwich, A. Are interventions theory-based? Development of a theory coding scheme. Health psychology : official journal of the Division of Health Psychology, American Psychological Association 29, 1-8, doi:10.1037/a0016939 (2010).

18 Cane, J., O'Connor, D. \& Michie, S. Validation of the theoretical domains framework for use in behaviour change and implementation research. Implementation science : IS 7, 37, doi:10.1186/1748-5908-7-37 (2012).

19 Fisher, W., Fisher, J. \& Shuper, S. Advances in Experimental Social Psychology. (2014).

20 El-Sayed, A. \& Galea, S. (Oxford University Press, Oxford, 2017).

21 Vries, H. D. \& Mudde, A. N. Predicting stage transitions for smoking cessation applying the attitude-social influence-efficacy model. Psychology and Health 13, 369-385 (1998).

22 Painter, J. E., Borba, C. P., Hynes, M., Mays, D. \& Glanz, K. The use of theory in health behavior research from 2000 to 2005: a systematic review. Annals of Behavioral Medicine 35, 358 (2008). 
23 Rosenstock, I. M. Historical origins of the health belief model. Health education monographs 2, 328-335 (1974).

24 Fisher, J. D. \& Fisher, W. A. Changing AIDS-risk behavior. Psychological bulletin 111, 455 (1992).

25 Bandura, A. Social foundation of thought and action: A social-cognitive view. Englewood Cliffs (1986).

26 Ajzen, I. The theory of planned behaviour. Organizational Behaviour and Human Decision Processes, 50, 179-211. De Young, 509-526 (1991).

27 DiClemente, C. C. et al. The process of smoking cessation: an analysis of precontemplation, contemplation, and preparation stages of change. Journal of consulting and clinical psychology 59, 295 (1991).

28 Hastings, J. in The Gene Ontology Handbook 3-13 (Springer, 2017).

29 Judea, P. Causality: Models, Reasoning, and Inference. (Cambridge University Press, 2000).

30 VandenBos, G. R. APA dictionary of psychology. (American Psychological Association, 2007).

\section{Funding and acknowledgements}

We are particularly grateful to the theory authors and experts who commented on the construct definitions and theory representations: Icek Ajzen (TPB), James Annesi (SCT), Carlo DiClemente (TTM), William Fisher (IBM), and Vic Strecher (HBM). We are grateful to Kate Sheals (KS) for assistance with coding the theories and drafting the paper. We are also grateful to Marie Johnston for early discussions about this piece of work and to Marta Marques, Alison Wright, Claire Garnett, Artur Direito, Hilary Groarke, Holly Walton, and Tracey Revenson who have kindly assisted with the drafting of the paper. This work was also supported by a grant from the UK Medical Research Council (grant number MR/L011115/1) and by a National Institute of Health Research Senior Investigator's award held by SM. RW's contribution was part funded by Cancer Research UK. The funders had no role in study design, data collection and analysis, decision to publish or preparation of the manuscript.

\section{Competing interests}

RW has undertaken research and consultancy from companies that develop and manufacture smoking cessation medicines (Pfizer, GSK, J\&J).

\section{Contributions}

RW contributed to study conception, revised coding of theories and led on preparation of the manuscript. SM conceived the project, and contributed to manuscript preparation. LCB, RC and CG undertook initial coding of theories, contributed to study conception and commented on manuscript drafts. $\mathrm{CG}, \mathrm{JH}$, and $\mathrm{CL}$ contributed to manuscript preparation. 